INVESTIGACIÓN

Recibido: 04/03/2019 --- Aceptado: 29/04/2019 --- Publicado: 15/09/2019

\title{
EL DISCURSO REFERIDO EN LOS ARTÍCULOS DE OPINIÓN. ANÁLISIS DEL DIÁLOGO EN LAS COLUMNAS DE ALFONSO SÁNCHEZ
}

\section{The speech referred in the opinion articles. Analysis of dialogue in the columns of Alfonso Sánchez}

\author{
María Ángeles Villa García1. Universidad Católica San Antonio de Murcia (UCAM), \\ Murcia. España. \\ mangelesvilla@hotmail.com
}

(1D) (3) Enrique Arroyas Langa. Universidad Católica San Antonio de Murcia (UCAM), Murcia. España.

earroyas@ucam.edu

\section{RESUMEN}

La polifonía es un rasgo característico del discurso periodístico. A través de la representación de distintas voces se da entrada a la diversidad interpretativa del contexto social. Este trabajo pretende reflexionar sobre el diálogo como recurso retórico en el artículo de opinión. Nuestra hipótesis es que el discurso referido es una técnica que produce efectos retóricos que, en el caso de las columnas, contribuyen a reforzar su poder persuasivo. El objetivo es definir y describir la utilización del discurso referido en las columnas y analizar sus efectos estéticos y cognitivos. Para ello se analizan los componentes dialógicos de diez columnas escritas en el diario Informaciones (1954 1980), por el periodista Alfonso Sánchez, pues según nuestra hipótesis este autor recoge la tradición del artículo de costumbres en un momento de renovación del género de opinión en España. El análisis retórico y narratológico que llevamos a cabo muestra que la columna de Sánchez interpreta la realidad a través de una polifonía de voces, dirigidas por un yo narrador que actúa como testigo. Mediante la apertura a las voces de los personajes, el discurso referido aumenta el dinamismo de los hechos narrados, aporta verosimilitud y, limitando la presencia del narrador, abre el discurso a una pluralidad de enfoques.

1 María Ángeles Villa García: Licenciada en Periodismo en la Facultad de Ciencias Sociales de la Universidad Católica San Antonio de Murcia. Actualmente realiza el Doctorado en la Universidad Católica de Murcia, en el programa de Ciencias Sociales. Editora de informativos en la Televisión Autonómica de Murcia. 
Villa García, M. A., y Arroyas Langa, E. El discurso referido en los artículos de opinión. Análisis del diálogo en las columnas de Alfonso Sánchez

PALABRAS CLAVE: artículos - columna - opinión - diálogo - retórica - periodismo narrativa.

\begin{abstract}
Polyphony is a characteristic feature of journalistic discourse. Through the representation of different voices, the interpretative and ideological diversity of the social context is introduced. In the discourse the different voices relate to each other and to the voice of the narrator. This work aims to reflect on the dialogue as a rhetorical resource in the opinion article. Our hypothesis is that reported speech is a technique that produces rhetorical effects, which, in the case of opinion columns, contribute to the reinforcement of its persuasive power. Thus the objective of this work is to define and describe the use of reported speech in opinion columns and analyze its aesthetic and cognitive effects. For this purpose, the dialogical components of ten columns written by the journalist Alfonso Sánchez in the Informaciones newspaper will be analyzed, since according to our hypothesis this author picks up the tradition of the article of customs at a moment of renewal of the opinion genre in Spain. The rhetorical and narrative analysis that we carried out shows that Sánchez's column interprets reality through a polyphony of voices, directed by a narrating self that acts as a witness. Through the opening to the voices of the characters, the discourse referred to increases the dynamism of the narrated facts, provides verisimilitude and, limiting the presence of the narrator, opens the discourse to a plurality of approaches.
\end{abstract}

KEY WORDS: articles - column - opinion - dialogue - rhetoric - journalism - narrative.

\title{
O DISCURSO REFERIDO NOS ARTIGOS DE OPINIÃO. ANALISES DO DIÁLOGO NAS COLUNAS DE ALFONSO SANCHEZ
}

\section{RESUME}

A polifonia e um traço caraterístico do discurso jornalístico a traves da representação de distintas vozes da entrada a diversidade interpretativa do contexto social. Este trabalho pretende reflexionar sobre o diálogo como recurso retorico no artigo de opinião. Nossa hipótese e que o discurso referido e uma técnica que produz efeitos retóricos que, no caso das colunas, contribuem a reforçar seu poder persuasivo. $O$ objetivo e descrever a utilização do discurso referido nas colunas e analisar seus efeitos estéticos e cognitivos. Para isso se analisa os componentes dialógicos de dez colunas escritas no jornal Informaciones (1954-1980), pelo jornalista Alfonso Sanchez que segundo nossa hipótese este autor continua a tradição do artigo de costumes em um momento de renovação do gênero de opinião na Espanha. A análises retorica narratológica que utilizamos mostra que a coluna de Sanchez interpreta a realidade através de uma polifonia de vozes, dirigidas por um EU narrador que atua como testemunha. Mediante a abertura das vozes dos personagens, o discurso referido aumenta o dinamismo dos fatos narrados, 
Villa García, M. A., y Arroyas Langa, E. El discurso referido en los artículos de opinión. Análisis del diálogo en las columnas de Alfonso Sánchez

aporta veracidade, limitando a presença do narrador, abre o discurso a uma pluralidade de enfoques.

PALAVRAS CHAVE: artigos - coluna - opinião - retórica - jornalismo - narrativa.

Como citar el artículo:

Villa García, M. A., y Arroyas Langa, E. (2019). El discurso referido en los artículos de opinión. Análisis del diálogo en las columnas de Alfonso Sánchez. [The speech referred in the opinion articles. Analysis of dialogue in the columns of Alfonso Sánchez]. Vivat Academia. Revista de Comunicación, 148, 101-119.

DOI: http://doi.org/10.15178/va.2019.148.101-119

Recuperado de http://www.vivatacademia.net/index.php/vivat/article/view/1167

\section{INTRODUCCIÓN}

\subsection{El diálogo como recurso retórico y los estilos de citación}

El diálogo es el recurso retórico que da voz a las figuras narrativas o personajes de una narración. Entre los diferentes modos expresivos, el diálogo se entiende como un segmento narrativo que recoge la dinámica de la acción a través de la expresión de actos del lenguaje. De esta forma, los hechos lingüísticos imputables a los personajes se integran en el relato como representaciones de acciones verbales.

El estilo con el que el narrador reproduce el discurso de los personajes ha sido objeto de numerosas clasificaciones, con una serie de tipologías que dan cuenta de la complejidad de este modo de reproducción. Con vistas a analizar el valor estéticoontológico que asiste a cada estilo de citación, seguiremos el criterio de clasificación basado en la manera de incorporar las voces de las figuras que intervienen en la historia, según la terminología de Genette (1989).

- Discurso narrativizado. El narrador asume las palabras del personaje y las reproduce como acontecimiento más que como acto de habla, por lo tanto, quedan absorbidas en la perspectiva del narrador a modo de resumen. Se diluye la voz individual del personaje, con un efecto de distancia.

- Discurso traspuesto o trasladado. Equivale al estilo indirecto y al indirecto libre. También aquí el acto de habla pierde autonomía al quedar integrado sintácticamente en el discurso del narrador. Desaparece la literalidad de las palabras y el discurso alude solo a su sentido.

- Discurso referido o restituido. Cita literalmente las palabras del personaje en estilo directo, habitualmente con marcas delimitadoras (comillas o guiones). 
Villa García, M. A., y Arroyas Langa, E. El discurso referido en los artículos de opinión. Análisis del diálogo en las columnas de Alfonso Sánchez

- Discurso inmediato. El discurso del personaje a modo de monólogo interior aparece de forma autónoma y separada del discurso del narrador sin ningún tipo de introducción separativa que sirva de advertencia al lector.

La intervención de las figuras en el discurso puede dar pie a otra clasificación del tipo de diálogo según intervengan uno o más interlocutores (monólogo y polílogo), según el destinatario de la enunciación (réplicas entre las propias figuras -vector interlocutivo-, hacia figuras externas a la narración -vector desviado- o hacia nadie en particular soliloquio- con el objetivo de dar a conocer un pensamiento) y según su función (interactivo -hace avanzar el relato- y narrativo -narran acontecimientos extraescénicos, del pasado o del futuro, y por lo tanto introducen una narración dentro de la narración).

Como estilos de citación, la teoría distingue también entre los actos de habla y los actos de pensamiento. Esta es, no obstante, una peculiaridad de la narrativa de ficción que, a priori, quedaría más allá de los márgenes del discurso periodístico. De todas formas, como un recurso que ficcionaliza el discurso se puede plantear también en el análisis de textos periodísticos. García Landa (1998) expone las diferentes formas que tiene el narrador de plasmar el mundo interior verbalizado de los personajes: pensamiento indirecto, como una forma de citación del pensamiento de un personaje por parte del narrador que permite explorar su conciencia y por lo tanto profundiza en sus motivaciones con gran penetración analítica; pensamiento indirecto libre, donde se diluye la diferencia entre palabra pronunciada y palabra pensada con ausencia de verbos introductorios; pensamiento directo, como una transposición de la actividad mental del personaje en estilo directo; el monólogo, como el pensamiento de un personaje claramente diferenciado del discurso del narrador; y el soliloquio, como una combinación de monólogo interior y discurso narrativo coloquial donde se simula la situación comunicativa, una meditación en voz alta sin un interlocutor claro.

Los efectos comunicativos y narrativos de cada una de estas formas de citar hacen referencia a la intromisión en la intimidad del personaje, a su autonomía expresiva o a la intervención del narrador. El diálogo es la forma más clara de discurso referido directo o restituido en el que las palabras del personaje se diferencian del discurso del narrador ya que vienen introducidas por dos puntos, guiones, con interpolaciones del narrador o sin ellas. Suelen incluir además deícticos o locuciones adverbiales que señalan el tiempo del personaje. La intervención del narrador se limita a seleccionar las palabras, acotarlas e introducirlas, sin manipular el discurso citado, y así quedan separados los discursos del personaje y del narrador.

En el periodismo el diálogo es un modo de citación predominante en las entrevistas, mientras que en otros géneros informativos se prefiere el estilo directo, pero sin introducción de guiones ni marcas lingüísticas, de modo que los discursos de las

Vivat Academia. Revista de Comunicación. 15 septiembre 2019/15 diciembre 2019, nº 148, 101-119 
Villa García, M. A., y Arroyas Langa, E. El discurso referido en los artículos de opinión. Análisis del diálogo en las columnas de Alfonso Sánchez

diferentes voces quedan yuxtapuestos a través del punto y seguido, pero con una clara distinción entre ambos para el lector. También abunda el discurso cuasi-directo, o estilo mixto, con una sintaxis propia del estilo directo libre, pero con marcas como las comillas que diferencian las palabras del personaje. En este último caso, el sujeto de la enunciación transmite el discurso del personaje intentando preservar la objetividad de la citación con una combinación de discurso directo y discurso indirecto que es claramente detectable por el receptor. Las palabras del personaje están integradas sintácticamente en el discurso del narrador, pero diferenciadas a través de las comillas. Como una forma de apropiación por parte del narrador de la enunciación ajena puede considerarse también la intertextualidad, cuando se integra un texto ajeno en el propio discurso a través de la citación (Molero de la Iglesia, 2004).

\subsection{Los efectos del diálogo: función referencial y veracidad}

Uno de los aspectos de los que más se ha ocupado la teoría literaria es la relación entre el texto y la realidad, el problema de la representación, que en el caso de los discursos periodísticos cobra una especial importancia al ser un tipo de textos en los que el contrato realista entre autor y lector es fundamental, pues más allá del debate teórico sobre cuál es el referente real en la literatura, el periodismo parte de la premisa de que su propósito es hablar del mundo.

La teoría de las funciones lingüísticas de Jakobson (1984) concluía que todo texto cumplía una variedad de funciones, entre la función poética y la referencial, y que el predominio de una sobre otra podía servir de criterio para la identificación de los géneros: mientras que en la literatura la función poética era la dominante, en el periodismo prevalece la función referencial o denotativa. Las teorías literarias más en boga a finales del siglo pasado marginaban en el análisis narrativo todo lo que concernía a la semántica, la representación de lo real y la descripción, pues se asumió la idea de la desconexión radical entre texto literario y mundo. La crisis de la 'mimesis' reducía la cuestión de la representación a lo verosímil, un código aceptado por el lector, una ilusión (Compagnon, 2015).

Esta desconfianza hacia la capacidad de las palabras para captar lo real alcanza también al periodismo, un ámbito que desde la segunda mitad del siglo pasado ha visto cómo sus convenciones discursivas se han puesto en entredicho hasta dar lugar a una mezcla de géneros que, en sus momentos más polémicos, ha llevado a la confusión con la ficción. Al igual que los formalistas y estructuralistas consideraban el lenguaje como una cárcel (Jameson, 1980), los autores del giro lingüístico denunciaron el periodismo como una trampa (Burguet, 2008, Chillón, 2014). Se pasó de un periodismo objetivista basado en una confianza inocente en la representación de lo real a un periodismo escéptico que ponía bajo sospecha cualquier representación de lo real y lo reducía todo a interpretaciones subjetivas (Arroyas, 2009). 
Villa García, M. A., y Arroyas Langa, E. El discurso referido en los artículos de opinión. Análisis del diálogo en las columnas de Alfonso Sánchez

Sin embargo, lo que era accesorio para la literatura en el caso del periodismo seguía siendo un criterio básico en la búsqueda de la veracidad de sus textos. Se trata de un debate que sigue vivo en la discusión teórica y que ofrece argumentos interesantes para el análisis narrativo. Aunque el realismo se consideraba una simple convención, no dejó de estudiarse como efecto formal. Como explica Compagnon (2015, p. 128), aunque la literatura no puede copiar lo real sigue siendo capital estudiar cómo nos hace creer que copia lo real. También este enfoque era válido para un periodismo envuelto en el giro lingüístico y la crisis de la objetividad.

Entre todos los recursos retóricos encaminados a reforzar la función referencial de los textos, el discurso referido ocupa un lugar destacado. Lo verosímil como sustituto de lo realista actúa como ilusión referencial. Aunque no se copie lo real, el texto no pude dejar de resultar convincente para el lector. Lo que ocurre es que la referencia no es la lejana e inalcanzable realidad (en periodismo se podría decir la incierta verdad de los hechos) sino una realidad intermedia, otras visiones sobre lo real, otros textos, la intertextualidad y, en el sentido más amplio que le da Bajtin (1989), el dialogismo, conceptos que resultan muy clarificadores sobre el alcance de los textos, tanto literarios como periodísticos, y por lo tanto también de los textos periodístico-literarios, como es el caso de las columnas de opinión. Bajtin interpreta un texto como una estructura compleja de voces, realidad, historia y sociedad. Este enfoque resulta muy oportuno para el análisis del texto periodístico pues este actúa como una relación de textos, voces, citas en un entramado interpretativo sobre lo real cuyo destinatario es un lector, con quien se construye un sentido referido al mundo real, un enfoque, asimismo, que en el caso de los géneros de opinión como la columna puede contribuir al estudio de los recursos narrativos destinados a la persuasión en un tipo de texto que tiene rasgos literarios.

\subsection{Carácter dialógico y polifónico de los artículos: perspectivismo y multifocalidad}

Tanto la intertextualidad, recurso fundamental en el periodismo que tiene por objeto dar cuenta de lo ocurrido y que en gran parte hace referencia a actos verbales y textuales preexistentes, como el discurso referido de actos de habla y pensamiento son elementos que configuran el carácter dialógico y polifónico que se ha destacado como constitutivo de los géneros narrativos (Bajtín, 1989, Reyes), pero también del discurso periodístico, donde la concurrencia de voces heterogéneas, como una forma de representar diferentes puntos de vista, forma parte de su método de interpretación de la realidad (Fernández Lagunilla y Pendones, 1993, Amado, 2014).

Una narración puede contar con varios narradores en función de su participación en la historia, el número de historias que se cuentan y el papel que cada narrador desempeña en ellas. De esta manera, el diálogo multiplica el número de historias que se cuentan en una narración al convertir a una figura en narrador, lo que se denomina 
Villa García, M. A., y Arroyas Langa, E. El discurso referido en los artículos de opinión. Análisis del diálogo en las columnas de Alfonso Sánchez

narrador figural, un narrador que tiene la peculiaridad de vivir las circunstancias que narra desde dentro de la historia (Spang, 2009). Así pues, el primer efecto del diálogo es la dramatización de la narración, que se hace más compleja por la multiplicación en el relato de figuras, historias, tiempo y espacio.

A partir de aquí, resulta interesante analizar, desde el punto de vista de la ficcionalización, la veracidad y la verosimilitud, la relación entre el narrador principal y los narradores figurales del diálogo: si su saber es igual que el de los personajes o si sabe más o menos, pues su omnisciencia o equisciencia tendrá efectos de verosimilitud. Como espacio creador de instancias narrativas, el discurso referido tiene una doble cara: un efecto de ficcionalización a la vez que de verosimilitud. La ficcionalización consiste en "la plasmación de elementos figurales, espaciales y temporales aptos para ilustrar y hacer comprensible la problemática y el tema y, por tanto, el mensaje en uno y otro modo. Y en último término hacer transparente el ser, descubrir lo uno, lo verdadero y lo bueno en unas circunstancias determinadas construidas a propósito por el autor" (Spang, 2009, p. 224). No obstante, en la medida en que una figura se convierte en narrador de su propia historia en primera persona se produce también un efecto de verosimilitud.

Por otra parte, el uso del perspectivismo narrativo y de la multifocalidad expresiva y descriptiva como técnica usada en la elaboración de los artículos amplía la complejidad psicológica y caracterológica del relato y lo acerca al lector. El diálogo tiene el efecto de resaltar la inmediatez de los acontecimientos. Mediante la apertura a las voces de los personajes, el discurso referido aumenta el dinamismo de los hechos narrados. De este modo, aporta verosimilitud al ajustarse a las reglas del comportamiento humano. Hay una dimensión lúdica en el que los actores juegan un papel con el objetivo de crear la ilusión de realidad. "El drama puede entenderse como experimento lúdico-existencial en el que se crea la ilusión de realidad" (Spang, 2009, p. 191).

Finalmente, el perspectivismo dialógico contribuye también a abrir la narración a una pluralidad de enfoques mediante el intercambio verbal de los personajes como una forma de limitación de la presencia del narrador, que pasa a un segundo plano para crear el efecto de que no está por encima de sus lectores y la ilusión de no imponer sus puntos de vista como tal.

\subsection{El diálogo en el artículo de costumbres}

El perspectivismo dialógico era un elemento esencial en el artículo de costumbres y así ha sido estudiado en la obra de Larra, que destaca por su capacidad para reflejar los diversos enfoques y las perspectivas múltiples en la presentación de los hechos por medio del diálogo de los personajes. Con esta yuxtaposición de las perspectivas opuestas, Larra ofrece al público "lo que es por todos conocido pero con un nuevo 
Villa García, M. A., y Arroyas Langa, E. El discurso referido en los artículos de opinión. Análisis del diálogo en las columnas de Alfonso Sánchez

punto de vista. Como buen escritor costumbrista, nuestro autor finge sentirse sorprendido por todo aquello que le rodea, se considera un habitante ingenuo de un país cuyas costumbres simula no conocer para aparecer como extranjero en su propia patria. Su acierto en la ficción de la sorpresa, su redescubrimiento de lo ya conocido le permite censurar alguno de los vicios de la sociedad en que vive, a la par que deja entrever posibles soluciones" (Cantero, 2011).

El artículo de costumbres se sitúa en una posición liminar entre el periodismo y la literatura, entre la narrativa factual y la ficcional. En este sentido, puede considerarse un intergénero, ya que se instaura en las primeras décadas del siglo XIX como una forma que comparte tanto características propias de diversos géneros periodísticos como otras exclusivas de géneros literarios, acabando por erigirse, una vez institucionalizado en las prácticas culturales de la época, como un género autónomo por derecho propio (Peñas, 2014).

Hacia finales del siglo XIX, el artículo redujo las dimensiones que tuvo en la etapa romántica y adquirió un aire más periodístico: predominaba en él la opinión directa sobre los asuntos de actualidad. Más tarde iría tomando el carácter de texto breve y elaborado que tiene en la prensa contemporánea. Entendido en su vertiente de género periodístico endógeno (Peñas, 2014), se desarrolla formalmente en virtud de necesidades puramente mediáticas; la prensa le facilita un soporte o cauce expresivo y le imprime determinadas convenciones -brevedad, condensación temática, dialogismo y actualidad-. A la vez, se desliza hacia los dominios de la literatura en su voluntad de desplegar un discurso imaginario, con tramas mínimas, personajes inventados, técnicas y estilos propiamente literarios, de ahí la importancia de considerar dicho artículo en su génesis histórico-literaria. Este tipo de artículo es realidad e imaginación con visión crítica y aguda de la vida humana; con un poco de filosofía y unas gotas de humor (Martín Vivaldi, 1993).

Por otra parte, en los artículos de costumbres hay una clara voluntad de mostrar la realidad tal cual es. Al mismo tiempo que elaboran una crítica de costumbres cimentada en el análisis social, reflejan en sus textos los objetos de sus observaciones con verismo, de ahí que el costumbrismo siempre se haya considerado un precedente esencial del posterior movimiento estético del realismo. Según Peñas (2014), el artículo de costumbres se avenía bien, por su propia naturaleza genérica, con este afán de acercar la literatura al público, pues se apela temáticamente a las raíces y tradiciones de la sociedad, a los usos y costumbres particulares y privativas del pueblo español, estrechando así un potente vínculo emocional con el público, cuyo retrato pretendía reflejar.

El artículo de costumbres solía contener una ficción mínima con una narración que envolvía un discurso moral de base. El costumbrismo choca entonces con una flagrante 
Villa García, M. A., y Arroyas Langa, E. El discurso referido en los artículos de opinión. Análisis del diálogo en las columnas de Alfonso Sánchez

paradoja: conforme avanza el siglo y se hace más evidente la necesidad de pintar la vida moderna, de hablar de lo actual, inmediato y contemporáneo, más se aleja el artículo de dicho propósito, inmerso en una espiral por la cual remite a su propio código metaliterario y autorreflexivo, así como a unos modelos que ya han entrado en decadencia.

Entronca con el artículo de costumbres decimonónico la crónica periodística de actualidad que combina, con mayor o menor intensidad, la crítica de costumbres, el apunte irónico, el dardo satírico, la reflexión moral y la mirada atenta que traduce, desambigua, glosa y retrata lo trivial, la costumbre de cada día (Peñas, 2014). La columna moderna hereda y absorbe todas esas tradiciones, las transforma y genera su propio horizonte de posibilidades. A modo de síntesis, se puede decir que en la columna desemboca el articulismo literario y costumbrista iniciado por Larra, la crónica y el artículo periodístico de los años sesenta y setenta, el resto de artículos de los intelectuales que colaboraban en los periódicos de un modo más o menos frecuente y lo que desde los años 50 se bautizó como columna periodística, de raigambre anglosajona estadounidense-, muy ligada al acontecer diario y más aparejada con la actualidad informativa y el comentario de lo que pasaba (López Pan, 1995, pp. 18-19).

Forneas (2005) asegura que "en nuestros días, la mayor parte de los artículos de costumbres adoptan la forma de columnas y se han transformado notablemente desde que, durante la primera mitad del siglo XIX, se consolidaron como subgénero periodístico y literario". En este tipo textos sobrevive, transmutado, el espíritu del artículo de costumbres, la nota de actualidad que enlaza con la obsesión de los primeros articulistas por captar la contemporaneidad, lo fugaz y transitorio del instante, o el factor sorpresa, componente intrínseco del carácter perspectivístico de toda literatura centrada, como esta, en ofrecer bajo nueva luz la imagen cotidiana, la costumbre.

Este tipo de columnas de carácter más narrativo que argumentativo, herederas del artículo de costumbres, se caracterizan además por su heterofonía (multiplicidad de voces) e incluso heteroglosia (presencia de distintos niveles de lengua), porque el columnista no sólo usa su propia voz, sino que esta se compone de las voces de otros, las voces de la sociedad (García Álvarez, 2007). Y no sólo existe esa pluralidad de voces en el mismo yo narrador, sino que además el columnista dibuja de manera directa o sutil un interlocutor imaginado, un otro con el que establecer su diálogo y completar el fin último de la comunicación.

La columna, que nace desde la perspectiva única del autor, tiene como fin ver la luz en un soporte social y ya de por sí polifónico. El columnista al construir su discurso construye su enunciado y este está compuesto por una polifonía de voces, aunque se presenten dirigidas bajo la batuta del yo narrador. 
Villa García, M. A., y Arroyas Langa, E. El discurso referido en los artículos de opinión. Análisis del diálogo en las columnas de Alfonso Sánchez

\subsection{La columna personal de Alfonso Sánchez en el diario Informaciones}

Los comienzos de la obra de Alfonso Sánchez en el diario Informaciones en los años 50 coinciden con la popularización del término columna para designar al artículo firmado que se publica con regularidad y que ocupa un espacio predeterminado en el periódico (Casals, 2000), un tipo de artículo de opinión en el que importa tanto la expresión como su contenido, la forma, como el fondo, $y$, por lo tanto, su calidad literaria.

La clasificación más inmediata que puede hacerse de la columna como género de opinión es aquella que la divide en dos grandes grupos: las columnas analíticas y las columnas personales. Trataremos aquí la columna personal, objeto de nuestro análisis, cuyos estudiosos la sitúan a mitad de camino entre literatura y periodismo: permite que el autor se explaye con la mayor libertad, pues su prestigio le coloca por encima de las exigencias diarias del colectivo periodístico, sin sujetarse a mayores disciplinas, y su firma es suficiente aval para que los lectores le busquen por sí mismo, ya que confían en el valor o la gracia de unos escritos cuyo pacto de lectura se basa en gran medida en la confianza.

La columna personal es una artística síntesis entre la racionalidad y la subjetividad, como si se tratara del sincretismo más gratificante de todo lo que ha constituido nuestra historia intelectual desde el siglo XVIII. César González Ruano reconoció que su experiencia personal le enseñó que es precisamente la intimidad, la confidencia, la confesión de lo que individualmente ocurre, lo que resulta más atrayente y popular. Este tipo de columnas, a caballo entre el periodismo y la literatura, es una narración en la que, como en ninguna otra, el lector tiene más la sensación de estar escuchando la opinión personal del periodista y participando de su diálogo y debate interno, que estar enfrentándose a la lectura solitaria de un texto literario.

Además de por su carácter narrativo y descriptivo de usos, tradiciones, celebraciones y personajes característicos de su época, las columnas de Alfonso Sánchez son un reflejo de la retórica del artículo costumbrista también por su carácter dialógico y polifónico. Multitud de ejemplos de polifonía se encuentran en sus columnas cuando recoge esas otras voces de la sociedad plagando sus textos de manera consciente o inconsciente de heterefonía través del diálogo.

La trayectoria de Alfonso Sánchez está estrechamente unida a la prensa de Madrid, en cuyas cabeceras colaboró sin interrupción entre los años 1950 y 1981. Durante el franquismo eludió siempre cualquier exaltación o crítica, optando por el temario social y cultural en la primera época, y más tarde por la observación de costumbres.

Sánchez dedicó cientos de columnas a la sociedad de Madrid, sobre todo a la alta sociedad, gente conocida de la capital, esos nombres que destacaba en negrita o en mayúsculas para que los lectores focalizaran su mirada. 
Villa García, M. A., y Arroyas Langa, E. El discurso referido en los artículos de opinión. Análisis del diálogo en las columnas de Alfonso Sánchez

Alfonso Sánchez inicia sus trabajos de periodista en El Alcázar como crítico de cine, además de colaborar en las revistas Primer Plano, Cámara, Revista Internacional de Cine o Tele-Radio. Desde los primeros números colaboró con La Codorniz en la sección '¿Está usted seguro?' En 1951 comienza a escribir en la Hoja del Lunes y más tarde, en 1954, en el diario vespertino Informaciones hasta 1980. Su primera columna en el diario Informaciones "Por el sol y a ver al 'duque'" la escribió el 1 de noviembre de 1954. La última, "Hasta pronto, con cine", salió el 2 de febrero de 1980, coincidiendo con el cierre del periódico.

El periódico Informaciones fue un periódico conservador, pionero de la prensa vespertina de Madrid, fundado en 1922 por el periodista y político aragonés Leopoldo Romeo. Tras el final de la contienda el diario pasó a ser dirigido por el periodista Víctor de la Serna, con una acentuada línea editorial germanófila. En 1956 fue adquirido por la empresa Bilbao Editorial y en 1967 pasa a depender de la Unión Democrática Española. Un año después, el rotativo pasó a ser propiedad de un grupo de banqueros encabezado por Emilio Botín y fue esa su etapa de modernización y expansión. En ese Informaciones renovado, Víctor de la Serna Gutiérrez-Répide es nombrado Consejero Delegado, su hermano Jesús de la Serna, director y el joven periodista Juan Luis Cebrián, redactor jefe y luego subdirector. Durante ese período se produce una expansión del diario hasta alcanzar los 74.000 ejemplares diarios en 1976 y, por sus páginas, alentadas por los hermanos de la Serna y Cebrián, pasa el mejor plantel periodístico del momento.

Sánchez fue también docente de la Complutense y corresponsal y jurado en los festivales de cine europeo más relevantes desde los años 50 hasta su muerte. A lo largo de su carrera ejerció de colaborador en Televisión Española, en programas de cine como En Antena, Panorama de Actualidad, Punto de Vista, Buenas Tardes o Revista de cine. Falleció el 8 de septiembre de 1981.

\section{OBJETIVOS}

En objetivo de este artículo es definir, describir y analizar la utilización del discurso referido como recurso retórico en el artículo de opinión, muy frecuente en las columnas de Alfonso Sánchez: lo verosímil como sustituto de la realidad para que resulte convincente al lector, a partir de la hipótesis de que las columnas de Sánchez son herederas del artículo costumbrista de Larra por su carácter dialógico y polifónico, además de por la descripción de usos y personajes de su época.

\section{METODOLOGÍA}

Para el análisis de los efectos persuasivos, estéticos y cognitivos de los componentes dialógicos de la obra periodística de Alfonso Sánchez, se han seleccionado diez columnas publicadas en el diario Informaciones desde 1954 a 1980 bajo el título “Mi 
Villa García, M. A., y Arroyas Langa, E. El discurso referido en los artículos de opinión. Análisis del diálogo en las columnas de Alfonso Sánchez

Columna". Se han escogido columnas de cada una de las tres etapas de su trayectoria profesional: inicio (años 50), consolidación (años 60) y madurez (años 70 y 80): "Acapulco en Ondarreta" del 9 de julio de 1956; "Lo abstracto como prenda de abrigo" del 24 de noviembre de 1960; "Ayer conocí a Doña Fabiola como un madrileño más" del 1 de diciembre de 1960; "La corbata" del 23 de octubre de 1975; "Con perfume en el bolsillo" del 17 de enero de 1976; "Toros y rumores" del 3 de junio de 1976; "Los populares de L.A.E." del 2 de febrero de 1977; “Esto empieza caliente, desde luego", del 8 de septiembre de 1977; "No se admiten perros" del 21 de julio de 1978 y "Estreno en calma" del 7 de octubre de 1978.

El análisis se lleva a cabo mediante un método de análisis retórico y narratológico (Arroyas y Berná, 2015). El análisis se ha llevado a cabo a partir del método retórico que aborda el texto como unidad significativa, relevante por sus aspectos sintácticos y semánticos, con una dimensión pragmática. Se diseñó una plantilla de análisis con las siguientes categorías:

\begin{tabular}{|c|c|}
\hline 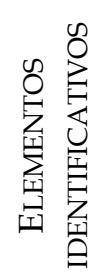 & $\begin{array}{l}\text { 1. Fecha } \\
\text { 2. Título de la columna } \\
\text { 3. Medio de publicación }\end{array}$ \\
\hline 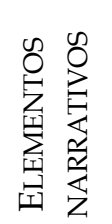 & $\begin{array}{l}\text { 4. Tema } \\
\text { 5. Enfoque } \\
\text { 6. Argumento } \\
\text { 7. Narrador } \\
\text { 8. Personajes }\end{array}$ \\
\hline 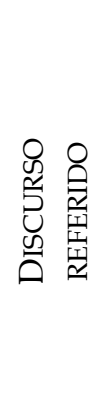 & 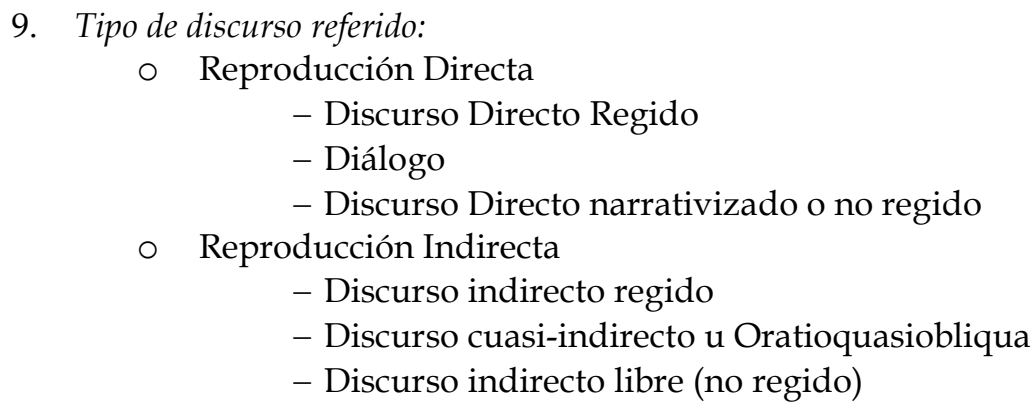 \\
\hline 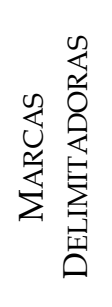 & $\begin{array}{l}\text { 10. Marcas delimitadoras: } \\
\begin{aligned} \circ & \text { Dos puntos } \\
\circ & \text { Punto y seguido } \\
\circ & \text { Comillas } \\
\circ & \text { Cursiva } \\
\circ & \text { Guiones } \\
\circ & \text { Sin marcas }\end{aligned}\end{array}$ \\
\hline
\end{tabular}


Villa García, M. A., y Arroyas Langa, E. El discurso referido en los artículos de opinión. Análisis del diálogo en las columnas de Alfonso Sánchez

\begin{tabular}{|c|c|}
\hline \begin{tabular}{l}
0 \\
$0_{0}^{0}$ \\
$\frac{0}{1}$ \\
\multicolumn{1}{|c}{}
\end{tabular} & \begin{tabular}{|rl} 
11. Verbos introductores: \\
$\quad$ & Circunstanciales \\
$\circ$ & Contextuales \\
$\circ$ & Elocutivos \\
$\circ$ & Nocionales \\
$\circ$ & Afectivos \\
& Sintéticos
\end{tabular} \\
\hline
\end{tabular}

Figura 1. Plantilla.

Fuente: Elaboración propia.

\section{ANÁLISIS Y DISCUSIÓN}

La modalidad expresiva predominante en las columnas analizadas es la mostrativa, con abundantes partes de discurso referido que se van intercalando con fragmentos narrativos, descriptivos y explicativos o valorativos:

"Es posible que la playa de Acapulco sea la hermosura que dicen. Era más hermosura Ondarreta en la mañana radiante, con el sol todavía sin quemar, con un agua limpia y fresca..." ("Acapulco en Ondarreta", 19-07-1956).

"Frente al Ayuntamiento, dos filas de guardias municipales en gran gala. Mucha gente. Iban llegando personalidades..." ("Ayer conocí a Doña Fabiola como un madrileño más", 1-12-1960).

Toda la narración está construida a partir de lo que el narrador-personaje cuenta, en primera persona, de lo que ha escuchado de otros durante la celebración de un cóctel, una exposición, una visita de la realeza, el rodaje de una película, una gala de entrega de premios, etc.

En la utilización del discurso referido destaca la reproducción directa, principalmente el discurso directo referido, aunque también recurre en la mayoría de las columnas analizadas, al diálogo:

Llegó CONCHITA MONTES luciendo al cuello un pañuelo que le ha regalado el tal Mathieu. Su pintura es muy decorativa en estas prendas. Le pregunté:

- Oye, Conchita, ¿abriga mucho lo abstracto?

La CONDESA DE YEBES, que estaba en el diálogo, contó algo bueno: - Una amiga mía oyó que Mathieu es hijo de un multimillonario y preguntó: "¿cuándo le echó de casa su padre?". ("Lo abstracto como prenda de abrigo", 24-11-1960).

Mayte hace siempre los honores con su simpatía, aunque nos tiene descuidado el cine. Se lo pregunto: 
Villa García, M. A., y Arroyas Langa, E. El discurso referido en los artículos de opinión. Análisis del diálogo en las columnas de Alfonso Sánchez

- ¿Para cuándo un Premio Mayte de Cine?

Hace un gesto de duda. Quizá el cine debiera situarla en sus películas. Es

guapa, inteligente,

con temperamento. Ella retruca:

- Anda, déjate de bromas. ("Los populares de L.A.E.", 2-02-1977).

Guiño el ojo a Rafael Azcona en solicitud de su complicidad y hago una nueva

pregunta:

-Y travestis ¿admiten ustedes?

El patrón o el maître se me quedan mirando con cara de no comprender nada.

Con cierta timidez responden:

-Pues, hombre, si vienen... ("No se admiten perros", 21-07-1978).

Coexisten dos discursos claramente diferenciados (narrador-protagonista y personaje-interlocutor), en el que el discurso del narrador rige sintácticamente el discurso del personaje a través de marcas formales (dos puntos y guion) y verbos dicendi o sentiendi, con algunos casos de deícticos y locuciones adverbiales que señalan al tiempo del personaje (en la mañana, después, el año que viene, luego, tiempo habrá, en otros lugares, largamente, saca tiempo, por una vez, este año, esta pausa, con calma, anoche alguien, ahora lo veo aquí, se va pronto, entre otros).

Junto a la literalidad de la cita, la inmediatez y cercanía que proporciona este tipo de discurso, además del ritmo ágil que le da a la narración, destacan en sus columnas la posición determinante del narrador, que controla el discurso ajeno como reproductor. Una posición reforzada por la utilización de la primera persona y la peculiaridad de que todas las intervenciones de otros personajes son siempre interpelaciones al propio narrador, lo que lo convierte en protagonista. Todo lo que se cuenta es percibido por el narrador como testigo, pero además como interlocutor primario, como un personaje. Abundan los ejemplos de este tipo, como el de la columna "Esto empieza caliente, desde luego" (8-09-1977):

"Llevaba mucho tiempo sin verle. El sábado le encontré en la peluquería...".

El efecto principal del discurso referido es de tipo narrativo. Se trata de intervenciones muy breves, fragmentarias, que, con pequeñas introducciones de los personajes, dinamizan el ritmo de la narración, visualizan las escenas $\mathrm{y}$, sobre todo, refuerzan la polifonía que favorece la refracción entre discursos de diferentes personajes. Las frases seleccionadas de los personajes sirven para respaldar las ideas del narrador, en alguna ocasión con el anonimato del autor de la cita. Un ejemplo lo encontramos en la columna "Esto empieza caliente, desde luego" (8-09-1977): 
Villa García, M. A., y Arroyas Langa, E. El discurso referido en los artículos de opinión. Análisis del diálogo en las columnas de Alfonso Sánchez

\section{"Al hablar de los sucesos con la farmacéutica, comentó: -Lo grave será si afectan a la metalurgia. Porque la metalurgia, Monsieur, es muy importante..."}

Algunas intervenciones a modo de diálogo sin réplica desempeñan una función puramente anecdótica, humorística y de creación de escenarios, aunque es importante también el recurso de caracterización del personaje como en la escena de la columna (“Estreno en calma", 7-10-1978) en la que el narrador tutea al camarero de la tasca:

$$
\text { - "oye, Manolo...". }
$$

La intervención del narrador se aprecia también mediante juicios de valor y recursos expresivos a través del tipo de verbo elegido y referencias a la situación anímica o espacio-temporal de los personajes. Con estos recursos expresivos, el narrador condiciona la imagen de los personajes y da al relato un tono que oscila entre la ironía, el humor y la crítica sutil. El verbo introductor desempeña un papel inicial respecto de los participantes de la situación comunicativa en términos pragmáticos.

El narrador da el contexto con el verbo, que es fundamentalmente contextual (dijo, comenta, pregunté, hablaban, contó, responden), elocutivo (susurra, pensé, rogó, sentenció, matizó, propongo, repitió) y nocional (susurra confidencialmente, se quejó, pregunten de repente, tranquilizó, consoló, se indigna, animan, etc.).

Junto al verbo son característicos en las columnas de Sánchez los pronombres 'me', 'nos', 'le' 'lo', 'la', 'las', entre otros, lo cual respalda el carácter personal de la narración y el protagonismo del narrador, con el consecuente efecto de cercanía, inmediatez y subjetividad, sin perder veracidad y realismo. Estos ejemplos los hallamos en: me confió, se nos reprochaba, le pregunté, la consoló, le corrigió, lo propuse, me dieron, entre otros.

El diálogo abre la narración a una pluralidad de enfoques mediante el intercambio verbal de los personajes limitando la voz del narrador, que no impone su punto de vista. Es una forma también de favorecer la crítica o descripción de costumbres desde la pluralidad de testimonios, captando la complejidad de la realidad social. De esta forma se pone en boca de otro la idea principal del artículo, a modo de sentencia, que luego repetirá el narrador. Este ejemplo lo encontramos en la columna ("Estreno en calma", 710-1970):

"López Sancho me lo decía a la salida: - La gente no tiene la menor idea de jaleo ni de volver a repetir tragedias".

El diálogo resalta la inmediatez de los acontecimientos y aumenta el dinamismo de los hechos narrados, lo que aporta verosimilitud al ajustarse a las reglas del comportamiento humano. El uso de narratarios permite a Alfonso Sánchez el dar

Vivat Academia. Revista de Comunicación. 15 septiembre 2019/15 diciembre 2019, nº 148, 101-119 
Villa García, M. A., y Arroyas Langa, E. El discurso referido en los artículos de opinión. Análisis del diálogo en las columnas de Alfonso Sánchez

entrada a sus artículos a otras voces distintas a la suya, con lo que esta polifonía refuerza el carácter retórico del texto, le ayuda a dirigir sus ideas, defenderlas, justificarlas y reforzarlas si es necesario. Tanto es así, que el diálogo se funde con la retórica con el fin de que la columna, bajo la dirección de una voz aparentemente dominante, esté llena de voces que resuenan en cada palabra.

\section{CONCLUSIÓN}

Una narración en primera persona a cargo de un narrador testigo que cuenta lo que ve y oye en diferentes encuentros con otros personajes es la modalidad más característica de las columnas de Alfonso Sánchez, en las que el diálogo desempeña un papel fundamental como recurso persuasivo. Tras el análisis se puede concluir que la columna personal de Sánchez se encuadra dentro de esos textos que no pretenden el reflejo de la realidad, sino que, alimentándose de ella, la reinterpretan a través de una polifonía de voces, dirigidas bajo la batuta del yo narrador, que actúa en todo momento como testigo en primera persona.

Las columnas de Alfonso Sánchez rescatan el carácter dialógico y polifónico propio de la retórica del artículo costumbrista. El discurso del narrador está teñido por los discursos de otros personajes representativos de los ámbitos sociales y culturales que frecuenta. A través del diálogo, la narración se dramatiza, haciéndose más compleja por la multiplicación en el relato de figuras, historias, tiempo y espacio. El uso del perspectivismo narrativo y de la multifocalidad expresiva y descriptiva como técnica usada en la elaboración de los artículos amplía la complejidad psicológica y caracterológica del relato y lo acerca al lector. Aunque este recurso tiende hacia la ficcionalización, en la medida en que una figura se convierte en narrador de su propia historia en primera persona se produce también un efecto de verosimilitud.

El diálogo también tiene el efecto de resaltar la inmediatez de los acontecimientos. Mediante la apertura a las voces de los personajes, el discurso referido aumenta el dinamismo de los hechos narrados. De este modo, aporta verosimilitud al ajustarse a las reglas del comportamiento humano.

El perspectivismo dialógico contribuye a abrir la narración a una pluralidad de enfoques mediante el intercambio verbal de los personajes como una forma de limitación de la presencia del narrador, que pasa a un segundo plano para crear el efecto de que no está por encima de sus lectores y la ilusión de no imponer sus puntos de vista como narrador, un tipo de discurso que se ajusta al tono irónico tan característico del estilo de Alfonso Sánchez. 
Villa García, M. A., y Arroyas Langa, E. El discurso referido en los artículos de opinión. Análisis del diálogo en las columnas de Alfonso Sánchez

\section{REFERENCIAS}

Amado, A. (2014). Los hechos y los dichos en las noticias: la polifonía del discurso periodístico. Romanica Olomucensia 26(2), 143-156. Recuperado de https://dialnet.unirioja.es/servlet/articulo?codigo $=5053281$

Arroyas, E. (2009). La objetividad y la función democrática del periodismo. Murcia: Ucam. Recuperado de https://www.academia.edu/2035998/La_objetividad_y_la_funci\%C3\%B3n_democr \%C3\%A1tica_del_periodismo

Cantero, V. (2011). El perspectivismo como técnica narrativa en los artículos de costumbres de Larra. La Laguna. Revista de Filología, 29, 21-36. Recuperado de https:/ / dialnet.unirioja.es/servlet/articulo? codigo $=3662466$

Aristóteles (2005).Retórica. Madrid: Alianza Editorial.

Armañanzas, E. y Díaz, J. (1996). Géneros de opinión. Bilbao: Eunsa.

Arroyas Langa, E. y Berná Sicilia, C. (2015).La persuasión periodística. Barcelona: UOC.

Bajtin, M. (1989). Teoría y estética de la novela. Madrid: Taurus.

Burguet, F. (2008). Las trampas de los periodistas. Barcelona: Trípodos.

Casals Carro, M. J. (2000). La columna personal: de esos embusteros días del ego inmarchitable. Estudios sobre el mensaje periodístico, 6, 31-51.

Chillón, A. (2014). La palabra facticia. Literatura, periodismo y comunicación. Barcelona: Universidad Autónoma de Barcelona.

Compagnon, A. (2015). El demonio de la teoría. Literatura y sentido común. Barcelona: Acantilado.

Fernández Lagunilla, M. y Pendones, C. (1993). Recursos polifónicos del narrador en el discurso periodístico. Revista de Filología Románica, 10, 285-294. https://core.ac.uk/download/pdf/38841629.pdf

Forneas Fernández, M. C. (2005). El artículo de costumbres: crónica, crítica, literatura y periodismo. Estudios sobre el mensaje periodístico, 5, 293-308. 
Villa García, M. A., y Arroyas Langa, E. El discurso referido en los artículos de opinión. Análisis del diálogo en las columnas de Alfonso Sánchez

García Álvarez, M. F. (2007).Las columnas de autor: Retórica y... ¿Diálogo? Caso práctico: La presencia del “otro" en el columnismo de Rosa Montero. Estudios sobre el mensaje periodístico, 13, 399-417.

Genette, G. (1989). Figuras III. Barcelona: Lumen.

Jakobson, R. (1984). Ensayos de lingüística general. Barcelona: Ariel.

Jameson, F. (1980). La cárcel del lenguaje: perspectiva crítica del estructuralismo y del formalismo ruso. Barcelona: Ariel.

León Gross, T. (2008). El artículo literario: Manuel Alcántara. Málaga, España: Servicio de Publicaciones de la Universidad de Málaga con la colaboración de la Fundación Manuel Alcántara.

López Pan, F. (1995). La columna como género periodístico. Pamplona: Eunsa.

Martín Vivaldi, G. (1993). Géneros periodísticos. Madrid: Paraninfo.

Molero De La Iglesia, A. (2004). Didáctica del texto narrativo. Estudio y análisis del discurso. Madrid: UNED.

Moreno Espinosa, P. (2002). Géneros para la persuasión en prensa: los artículos de opinión del diario El País. Revista Latina de Comunicación Social, 5(46). Recuperado de http:/ / www.redalyc.org/articulo.oa?id=81954612

Peñas Ruiz, A. (2014). El artículo de costumbres en España (1830-1850). Vigo. Academia del Hispanismo.

Perelman CH. y Olbrechts-Tyteca, L. (1989). Tratado de la argumentación. La nueva retórica. Madrid: Gredos.

Reyes, G. (1984). Polifonía Textual. La citación en el relato literario. Madrid: Gredos.

Santamaría Suárez, L. y Casals Carro, M. J. (2000): La opinión periodística. Argumentos y géneros para la persuasión. España: Fragua.

Spang, K. (2009). El arte de la literatura. Otra teoría de la literatura. Pamplona: Eunsa. 
Villa García, M. A., y Arroyas Langa, E. El discurso referido en los artículos de opinión. Análisis del diálogo en las columnas de Alfonso Sánchez

\section{AUTORES}

\section{María Ángeles Villa García}

Licenciada en Periodismo (junio 2001), en la Facultad de Ciencias Sociales de la Universidad Católica San Antonio de Murcia. Actualmente realiza el Doctorado en la Universidad Católica de Murcia, en el programa de Ciencias Sociales. Contrato de trabajo en Radio Nacional de España en la emisora territorial de Murcia. Tareas desempeñadas: redacción y presentación de boletines informativos, manejo de equipos y autocontrol; en la Agencia de Noticias Europa Press, Murcia. Tareas desempeñadas: redacción de noticias; en el periódico La Razón. Tareas desempeñadas: redacción de noticias; y en la Televisión Autonómica de Murcia, 7RM. Tareas desempeñadas: Editora de informativos.

mangelesvilla@hotmail.com

\section{Enrique Arroyas Langa}

Con un sexenio de investigación activo reconocido por la CNEAI (2006-2014), Enrique Arroyas Langa (Valencia, 1966), es Licenciado en Ciencias de la Información por la Universidad de Navarra y Doctor en Comunicación por la Universidad Católica San Antonio de Murcia. Desde el año 2003 es profesor de la Facultad de Comunicación de la UCAM, donde además de impartir la asignatura de Redacción Periodística, es el director del Título de Experto en Comunicación Política.

earroyas@ucam.edu

Orcid ID: https:/ / orcid.org/0000-0001-6578-1571

Google Scholar: https:/ / scholar.google.es/citations?user=9cZPGhAAAAAJ\&hl=es Índice H: 4 